\title{
Estudio y aplicación de un robot social a niños y niñas con necesidades de Atención Temprana
}

\author{
M.Martínez J.L.Guzmán* J.C.Moreno* \\ *Universidad de Almería, CIESOL, ceiA3, 04120 Almería \\ (mmm804@inlumine.ual.es, joseluis.guzman@ual.es, jcmoreno@ual.es)
}

\begin{abstract}
Resumen
Si bien la robótica industrial se ha desarrollado ampliamente durante los últimos treinta años en la industria manufacturera, la robótica de servicio se encuentra en pleno desarrollo, presentando grandes posibilidades de innovación y con gran potencial de crecimiento, donde cada vez los robots poseen mayor capacidad para interactuar con las personas. Basándose en esta habilidad, jugarán un rol esencial en la sociedad en un futuro no muy lejano. En este estudio, la motivación es analizar cómo funciona el robot social Aisoy1 desde el punto de vista tecnológico, y aplicar todo su potencial y las características que posee, en el diseño de actividades que ayuden a los niños y niñas para una mejor calidad de vida. Los resultados obtenidos son positivos, ya que teniendo en cuenta que un tratamiento se desarrolla en un periodo largo de tiempo, con el apoyo del robot, en un corto periodo, se han mostrado mejoras en la comunicación respecto al inicio del presente proyecto, como mayor vocalización, repetición de palabras, mejoría en la asociación de emociones y colores o mayor interacción con el entorno, que en un principio no existían o eran limitados.
\end{abstract}

Palabras clave: Robótica social, Aisoy1, Atención Temprana, Python, Raspberry Pi.

\section{Introducción}

La robótica de servicio puede dividirse en dos amplios apartados: servicios personales, como asistencia a niños, discapacitados y personas mayores, etc.; y servicios profesionales, como limpieza del hogar, medicina o vigilancia urbana. El presente artículo se centra en la aplicación de la robótica de servicio personal para la asistencia y apoyo a niños con necesidades especiales, concretamente en Atención Temprana de 0 a 6 años.

La Atención Temprana se fundamenta sobre principios científicos de disciplinas como Psicología, Pediatría, Linguística, etc. y tiene como finalidad ofrecer a los niños con déficits o con riesgo de padecerlos, un conjunto de acciones compensadoras y optimizadoras que faciliten su adecuada maduración en todos los ámbitos y que les permita alcanzar el máximo nivel de desarrollo personal y de integración social [1]. Y es que los primeros años de vida en un ser humano es una etapa especialmente crítica, ya que se configuran las habilidades cognitivas, perceptivas, motrices, lingüísticas y sociales que posibilitarán una interacción adecuada con el mundo que le rodea y que le acompañarán a lo largo de su vida.

Se emplea el robot social Aisoy1, por su facilidad de programación al trabajar con software-libre, bajo coste de mercado y porque dentro de sus características funcionales posee la capacidad de expresar emociones. Todas estas características hacen que sea idóneo para el proyecto.

Las actividades se han desarrollado en el CAIT Jardines de La Pipa en Almería, con cuatro niños y niñas. Con la ayuda de terapeutas especialistas que han estado presentes en todo momento, se han llevado a cabo actividades previamente estudiadas y adaptadas a las limitaciones que puede presentar Aisoy1, para la mejor experiencia posible de los niños y niñas.

Diversas investigaciones ya han demostrado que los robots sociales poseen un efecto terapéutico positivo en niños y niñas con autismo, ya que pueden emplearse como herramienta para demostrar o enseñar comportamientos socialmente, que les ayuden a relacionarse. Por ello, una opción que se investiga y se ensaya es explorar qué posibilidades ofrecen los robots en el diagnósitco y tratamiento, en la mayoría de los casos de autismo, además de mejorar otros aspectos como la concentración, entablar interacciones sociales adecuadas y hacer de supervisor para comprobar si se realiza correctamente la actividad o no [2].

\section{Robot social Aisoy1}

Aisoy1 es un producto de la empresa española Aisoy Robotics S.L. Su primera versión data de 2010 [5]. Es una plataforma robótica flexible basada en un procesador ARM Cortex similar al que incorporan los teléfonos inteligentes comerciales [3]. Se clasifica como robot zoomórfico y algunas de 
las aplicaciones potenciales que posee se encuentran en domótica [4], educación, en ambientes terapéuticos para niños con problemas de desarrollo o para personas mayores, así como para entretenimiento.

En su conjunto, el robot incluye varios sistemas: sensorimotor, de reconocimiento, de diálogo y un sistema operativo que controla el comportamiento global de la plataforma [6].

\subsection{Hardware}

La versión de Aisoy1 con la que se ha trabajado incluye un ordenador de placa reducida (SBC) Raspberry Pi 2 Modelo B, lo suficientemente potente como para cubrir las necesidades del robot y gestionar todos los actuadores y sensores [7].

Los sensores son dispositivos que capturan información sobre las magnitudes físicas o cambios del entorno del robot para su posterior procesamiento. Se pueden distinguir en: cámara (USB 3 megapíxel) situado en el ojo izquierdo, para tomar capturas de imagen y reconocimiento de códigos QR; micrófono, para captar sonidos del entorno como aplicación en reconocimiento de voz (ASR); acelerómetro, para reconocer la inclinación en 3D que posee en cada momento; sensores táctiles, integra tres tipos (uno en la parte posterior de la cabeza y dos en ambos laterales de su cuerpo).

Como actuadores posee servomotores. Emplea cuatro para los movimientos de la cabeza (dos para la rotación del cuello izquierda y derecha, arriba y abajo), para los párpados (apertura y cierre), y otro para las cejas (arriba y abajo). El accesorio botmobile permite al robot desplazarse. Posee dos motores situados en la parte inferior del cuerpo para moverse hacia delante, hacia atrás y rotar en sentido izquierdo y derecho. También dispone de un led RGB, situado en su barriga, mediante el que es capaz de mostrar un amplio rango de colores. Un altavoz para reproducir cualquier sonido y hablar; y una pantalla situada en la boca del robot, con resolución 128x64 píxeles donde muestra gestos bocales o cualquier tipo de imagen o texto (ver Figura 1).

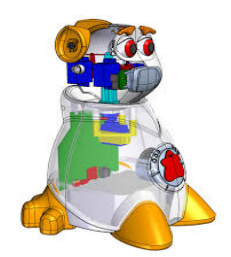

Figura 1: Estructura de Aisoy1

La apariencia de Aisoy1 es zoomórfica, es decir, posee apariencia animal. Los desarrolladores se inspiraron inicialmente en un cobaya por su aspecto divertido (ver Figura 2), curioso e inquieto, con una estética cartoon para que la interacción humano-robot fuese más amigable y cercana, evitando así el efecto del valle inquietante [11]. Sin embargo, para no atribuirle excesivamente la sensación de juguete, la versión final no adopta una apariencia totalmente animal, resultando el diseño final que puede verse en la actualidad [5].

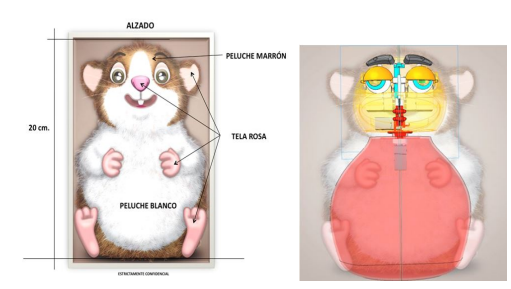

Figura 2: Apariencia física inicial y final de Aisoy1

\subsection{Software}

El sistema operativo del modelo empleado es AiROS5 SDK, basado en caracteríticas de ROS (Robot Operative System) y Raspbian. Con él se programan y ejecutan aplicaciones específicas para el robot llamadas Botapps. Posee además dos niveles de programación: interfaz de usuario y mediante lenguaje de programación a bajo nivel.

Como programación de interfaz gráfica se emplea el programa Scratch, una herramienta creada por el MIT, accesible a niños a partir de 8 años, muy intuitiva. Basta con arrastrar bloques preconfigurados al área de programación, creando una secuencia de tareas lógica y ordenada, y observar qué resultados producen en el robot al ejecutarlo.

En este trabajo se emplea programación a bajo nivel, una API disponible con lenguaje Python o $\mathrm{C}++$. En concreto, se emplea Python debido a su flexibilidad y sencillez. En total, existen 14 módulos distintos para controlar al robot, incluyendo librerías, paquetes y funciones que engloban todas sus funcionalidades. Además, se han empleado otras aplicaciones en paralelo al software del robot aprovechando el grado de libertad de programación que proporciona Raspbian, como la inclusión de nuevo hardware de entrada y salida al robot. Ejemplos de ello son: altavoces externos Logitech modelo S-100 black, proyector Mitshubishi Electric modelo EX200U y monitor LG modelo Flatron L1732S, ambos para salida de vídeo del robot; micrófono Philips modelo SBC MD 110/00 con su propia tarjeta de sonido USB 2.0 External Sound Card Adapter marca Ugreen y webcam modelo C170 Logitech, y nuevas aplicaciones como reconocimiento de colores, obteniendo en todos los casos resultados satisfactorios. 


\section{Estudio de Casos}

Tras una reunión inicial con los profesionales que trabajan en el centro, en el proyecto intervienen cuatro menores varones (V) cuyos diagnósticos iniciales son: Caso 1 (varón de 4 a 5 años y posible diagnóstico Trastorno Generalizado del Desarrollo (TGD)), Caso 2 (varón de 2 a 3 años y Trastorno Espectro Autista (TEA)), Caso 3 (varón de 2 a 3 años y Síndrome de Nicolaides-Baraitser (NCBS)) y por último, Caso 4 (varón de 3 a 4 años y Trastorno Generalizado del Desarrollo). Dichas características de interés se resumen en el Cuadro 1. Son elegidos debido a que los trastornos del desarrollo que poseen, pertenecen a un área común de intervención prioritario, donde resultan la comunicación y el lenguaje.

Cuadro 1: Casos a estudiar y diagnóstico inicial

\begin{tabular}{|c|c|c|c|}
\hline Niños & Sexo & $\begin{array}{c}\text { Edad } \\
\text { (años) }\end{array}$ & $\begin{array}{c}\text { Posible } \\
\text { Diagnóstico }\end{array}$ \\
\hline $\mathbf{1}$ & V & $4-5$ & TGD \\
\hline $\mathbf{2}$ & V & $2-3$ & TEA \\
\hline $\mathbf{3}$ & V & $2-3$ & NCBRS \\
\hline $\mathbf{4}$ & V & $3-4$ & TGD \\
\hline
\end{tabular}

Es necesario apuntar que, debido a la corta edad de los menores y sus características funcionales, exceptuando el Caso 3, aún no se ha realizado un diagnóstico formal que relacionen sus dificultades con un déficit de desarrollo concreto, por lo que se trabaja partiendo de un posible diagnóstico.

\section{Diseño de actividades}

En un principio los cuatro niños engloban los mismos objetivos específicos y generales a cumplir. Considerando los objetivos de la Atención Temprana [1], teniendo en cuenta la selección de actividades adecuadas para alcanzar progresivamente el máximo desarrollo y que éstas deben respetar los ritmos biológicos de los niños, se consideran los objetivos específicos siguientes:

1. Conocer los animales y sus onomatopeyas.

2. Nombrar los animales.

3. Identificar características de cada animal.

4. Asociar las imágenes de los animales con sus onomatopeyas.

5. Mostrar interés en la lectura del cuento.

6. Seguir la historia del cuento.

7. Realizar comentarios acerca del cuento.

8. Responder a preguntas sobre el cuento.
9. Discriminar los personajes de los diferentes cuentos.

10. Cantar las canciones.

11. Imitar los gestos que se realizan en ellas.

12. Conocer los instrumentos musicales.

13. Conocer los medios de transporte.

14. Conocer sonidos característicos del cuerpo humano (toser, aplausos...).

15. Conocer sonidos característicos del medio ambiente (lluvia, truenos...).

16. Asociar los sonidos con los instrumentos musicales correspondientes.

17. Asociar los sonidos con los medios de transporte correspondientes.

18. Asociar los sonidos del cuerpo humano con la imagen correspondiente.

19. Asociar los sonidos del medio ambiente con su imagen correspondiente.

20. Elegir una imagen en función de las características dadas (adivinanzas).

21. Conocer las emociones.

22. Identificar las emociones en el robot.

23. Identificar las emociones en sí mismo.

24. Asociar las emociones a situaciones de la vida cotidiana.

25. Reconoce las emociones en función de sus características físicas.

26. Conocer los colores.

27. Conocer las figuras geométricas básicas.

28. Elegir la figura adecuada en función de las características dadas (color y forma).

29. Clasificar objetos según color.

También se tiene en cuenta para programar, cuál es la mejor forma de interactuar entre el robot y los niños a la hora de realizar las actividades. Por ejemplo, respecto al lenguaje de Aisoy1, tanto si realizan bien la actividad como si no lo hacen, es necesario animar a los menores en todo momento, pues así no sentirán rechazo si fallan y cada vez lo harán mejor, como se ha comprobado analizando los resultados. Por tanto, se ha empleado constantemente el lenguaje positivo en cada respuesta y provocando la interacción hacia el menor, como por ejemplo: "imuy bien!, ¡maravilloso!, jsigue así!, ¡me encanta jugar contigo!, ¡hola! ¿cómo te ha ido hoy en el colegio?". Además, Aisoy1 llama a cada niño por su nombre para mostrar más cercanía y afecto.

Otro aspecto importante es el contacto físico del robot con los niños. El comportamiento de Aisyo1 será personalizado para cada uno, sobretodo 
mostrándose reactivo a las muestras de afecto o por seguimiento de instrucciones. Por ejemplo, si los menores lo tocan por los lados o detrás de la cabeza, el robot contesta y sigue con la actividad, emitiendo luces y sonidos. A continuación se resumen las distintas actividades.

\subsection{Figuras geométricas}

Consiste en la selección de una figura geométrica clasificada por color y forma dentro de un grupo más grande. En primer lugar, Aisoy1 muestra en la pantalla LCD la figura escogida en una imagen y en la barriga muestra el color. Con estos dos elementos el niño deberá escoger cuál es la correcta entre todas las figuras disponibles. Los recursos empleados son: programa de reconocimiento de colores y webcam USB.

\subsection{Puzle de emociones}

Aisoy1 realiza una emoción variando tres elementos: la posición de sus servomotores en cejas y párpados, la forma de la boca en la pantalla LCD y el color de la barriga. Todo ello compone una emoción que el niño debe asociar a un pictograma sobre estados de ánimo, y validarlo con Aisoy1 empleando códigos QR.

\subsection{Reconocimiento de emociones}

Esta actividad puede tener dos modos de realización: mediante la tecnología de reconocimiento de voz ASR o mediante reconocimiento de códigos QR. Aisoy1 en primer lugar muestra un estado de ánimo: alegría, enfado y sorpresa, y el niño debe adivinar cómo está. Además se le muestra la emoción con una fotografía de su propia cara para que asocie el estado de ánimo del robot al suyo propio (ver Figura 3).

Si se emplea ASR, el niño debe pronunciar la respuesta a Aisoy1 y en función de ésta el robot le contesta. Si se emplea el reconocimiento de código QR la comprobación del estado de ánimo se realiza mediante tarjetas con dicho código.

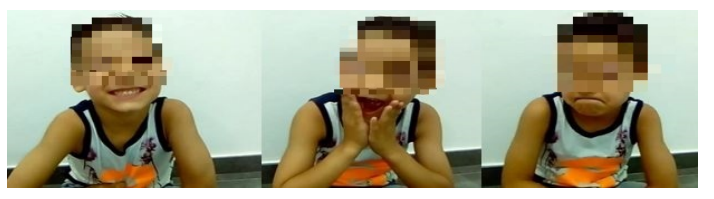

Figura 3: Emociones trabajadas para Caso 1

\subsection{Libro de los colores}

En esta actividad se ha confeccionado un libro con pegatinas de velcro para clasificar objetos cotidianos por colores. Aisoy1 muestra un color en su barriga y el niño debe mostrarle mediante una tarjeta de color cuál es. Se ha empleado el programa de reconocimiento de colores.

\subsection{Adivinanzas}

Aisoy1 muestra mediante el proyector o la pantalla externa una imagen con el enunciado de la adivinanza y tres posibles opciones. Esta actividad puede realizarse por verificación de códigos QR o por verificación de ASR. El niño elige una solución y la verifica con Aisoy1 enseñándole la tarjeta QR o diciéndole la palabra.

\subsection{Libros y cuentos}

Esta actividad fomenta la capacidad de observar e interpretar las imágenes, escuchar atentamente, orientar la atención en el robot o en la historia y enriquecer el vocabulario. Se han elegido libros que poseen ilustraciones claras, simples, coloridas y de gran tamaño.

\subsubsection{Cuento "Ronquidos"}

Aisoy1 relata el cuento a la vez que el niño lo lee físicamente y se pretende trabajar el vocabulario de los animales y las onomatopeyas del cuerpo humano. Según avanza el cuento, en función del animal o sonido, Aisoy1 imita dichas onomatopeyas a la vez que lo relata para que el niño posea una mayor compresión y asocie mejor los conceptos a través de ejemplos físicos.

\subsubsection{Cuento "El monstruo de colores"}

Está enfocado al tratamiento de emociones. A través de una historia amena y muy bien ilustrada, relata qué siente en cada emoción e igual que en el ejercicio "Puzle de emociones", asocia un color a cada estado de ánimo. Para una mejor comprensión por parte de los niños, se han empleado los mismos patrones de colores para todas las actividades relacionadas con las emociones. Aisoy1 relata el cuento realizando una pausa en cada emoción, para que el niño pueda observar bien las páginas y asimilar cada una correctamente.

\subsubsection{Cuento "Peppa Pig"}

Está orientado a los niños más pequeños de 2 a 3 años. Aisoy1 relata el cuento a un ritmo lento para que se puedan observar las imágenes y así asociar el texto a ellas para una mejor comprensión cognitiva. Además, se realiza una actividad posterior donde Aisoy1 hace una pregunta, por ejemplo, quién es Peppa Pig y suena un cerdo, y el niño debe elegir entre dos opciones la respuesta correcta 
a partir de dichos personajes. La verificación se realiza mediante códigos QR.

\subsection{Música}

Es una gran herramienta de estimulación sensorial, psicomotriz y lingüística. A la mayoría de los niños les agrada y les resulta más fácil imitar movimientos, gestos o sonidos en canciones con ritmo y repeticiones, que imitar simplemente algunas palabras. Por todo ello, aparte de emplear los vídeos musicales llamados "Cantajuegos" para seguimiento de instrucciones, Aisoy1 reproduce, al mismo tiempo que se realiza la actividad, música ambiental relajante de fondo para ayudarlos a concentrarse y al mismo tiempo, para desarrollar la habilidad de orientar la atención a otra tarea que se le pida y discriminar la música.

\subsubsection{Reconocimiento de onomatopeyas y sonidos}

En esta actividad, Aisoy1 reproduce un sonido cuyo tema puede ser animales, transportes, instrumentos musicales o cuerpo humano, y el niño debe elegir entre varias opciones cuál es el sonido correcto. A continuación le muestra al robot la tarjeta con el código QR y éste verifica si es correcto o no. En función del niño se repite el sonido tantas veces como sea necesario.

\subsubsection{Acciones}

A través de la pantalla externa o el proyector, Aisoy1 muestra una imagen real sobre una acción cotidiana que los menores suelen realizar, como lavarse los dientes, dormir, jugar, etc., y en la mesa se colocan todos los pictogramas de la actividad. Aisoy1 pregunta ¿qué hacen los niños en la imagen? y el menor debe responder en voz alta el pictograma que corresponde a la respuesta correcta.

\subsubsection{Vídeos musicales o Cantajuegos}

Se emplea una vez terminada la sesión o para conectar con el niño al principio, en función del estado de ánimo en el que se encuentre. El niño elige mediante tarjetas asociadas a las imágenes reales de las canciones qué vídeo quiere ver. Se lo enseña a Aisoy1 y una vez conectado el monitor o el proyector, Aisoy1 reproduce dicho vídeo y se visiona íntegramente.

\section{Resultados}

El periodo de realización de las sesiones ha sido de cinco meses aproximadamente, con una duración de una hora por sesión y acompañados siempre por uno o varios terapeutas expertos. Los resultados obtenidos se han basado en las evaluaciones que han realizado los terapeutas participantes en las actividades.

Respecto al resumen de actividades (ver Figura 4), puede verse que la más realizada es "Vídeos musicales" con un $32 \%$, debido a su dinamismo y a la capacidad de captar la atención del menor mientras realiza seguimiento de instrucciones básico. Con un $24 \%$ la segunda más empleada es "Reconocimiento de onomatopeyas y sonidos", pues el oído es un sentido que resulta más fácil de trabajar a edades tempranas. Además, la actividad les ayuda a concentrarse y focalizar la atención en una sola figura de todas las posibles, y también a aumentar el vocabulario. Con un $10 \%$ se emplea la identificación de emociones a través de la actividad "Puzle de las emociones", ya que aunque es la que más dificultad presenta para los niños, es muy importante realizarla como fase previa a la asociación de un rostro con un estado emocional concreto, y ,consecuentemente, a la asociación de las propias emociones del niño con los acontecimientos que viva en su vida diaria. Las demás actividades se han alternado durante las sesiones, por lo que en su mayoría presentan un porcentaje común entre un $4 \%$ y un $8 \%$, como "Figuras geométricas", "Adivinanzas", "Reconocimiento de emociones", "Libro de los colores", así como los diversos cuentos. Por otro lado, la actividad "Acciones" presenta un $1 \%$ debido a que se realizó sólo el último día de visita al centro, siendo parte de una propuesta de colaboración con M. A. Villegas [8]. Asimismo, la actividad "Reconocimiento de emociones", con un $3 \%$, presentó fallos con el software ASR de Aisoy1 al no reconocer correctamente la voz del menor ni de la terapeuta en el aula.

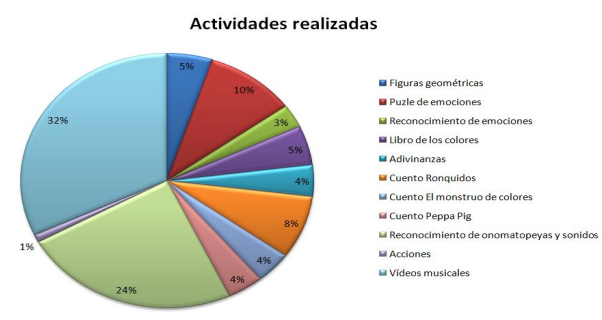

Figura 4: Porcentaje resumen de actividades

Para la valoración del progreso en los niños, se elaboró un cuestionario individualizado, en total cuatro casos distintos, en función de los objetivos específicos a conseguir. Para una mejor comparación de los resultados, se completaron dos veces: una vez previa a la primera sesión y una segunda tras la última sesión. Los cuestionarios poseen un máximo de 29 objetivos específicos o ítems (ver 
Apartado 4) con una puntuación gradual de 1 a 5 , valorando así el estado de las necesidades y habilidades. A continuación, se comentan los aspectos más relevantes de los resultados obtenidos.

\subsection{Caso 1}

Comparando antes y después de realizar las sesiones (ver Figura 5), se han mejorado notablemente los objetivos específicos relacionados con las actividades de lectura de cuentos, ya que antes poseía una puntuación de 2 y posteriormente mejora hasta 4 y 5 puntos.

Con las actividades de "Música", "Libro de los colores", "Figuras geométricas", "Puzle de emociones" y "Reconocimiento de emociones" se obtiene una puntuación de 5 , mientras que en un inicio la puntuación obtenida era de 3 y 4 puntos.

El niño con respecto a Aisoy1 se ha mostrado curioso desde un principio, llegando a interactuar con él, preguntar por él en otras sesiones y sin mostrar nunca rechazo.

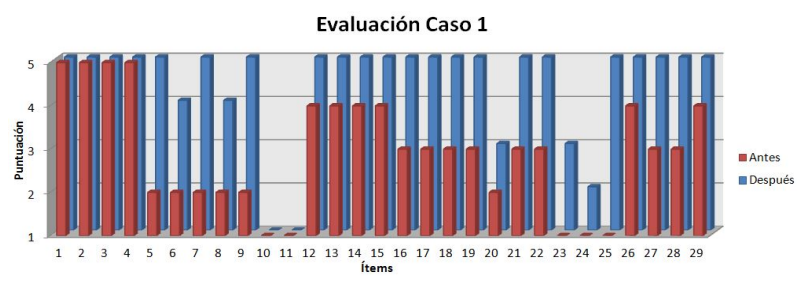

Figura 5: Resultados para evaluación Caso 1

\subsection{Caso 2}

No se aprecia una mejora general tan significativa como en el caso anterior (ver Figura 6), pues los objetivos específicos relaciones con la actividad "Libros y cuentos" y relacionados con la actividad "Puzle de emociones", como conocer las emociones (ítem 21), identificarlas en el robot (ítem 22), identificarlas en sí mismo (ítem 23) y asociarlas a situaciones de la vida cotidiana (ítem 24); se han mantenido como inicialmente con una puntuación de 1 .

Aún así, sí se han realizado logros como en "Música" relacionados con la discriminación auditiva, consiguiendo 3 y 4 puntos. También, con "Libros y cuentos" se ha mejorado el mostrar mayor interés (ítem 5) y discriminar los personajes (ítem 9), y con los "Vídeos musicales", se ha avanzado en objetivos como cantar las canciones (ítem 10) e imitar los gestos que se realizan en ellas (ítem 11), transformando la puntuación de 1 a 2 puntos. Además, relacionado con la actividad "Reconocimiento de emociones", se ha mejorado de 1 a 2 puntos el reconocimiento de éstas, como enfado o alegría (ítem 25).

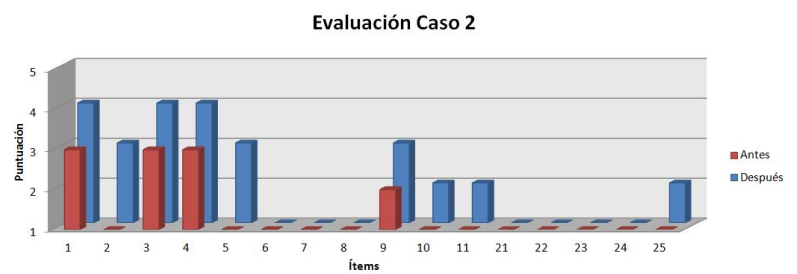

Figura 6: Resultados para evaluación Caso 2

Respecto a la relación con Aisoy1, el primer día de contacto, mientras el robot estaba apagado, el menor no le hizo caso, no le llamaba la atención. Sin embargo, al empezar a hablar y moverse éste, y con ayuda de la terapeuta, le prestó mucha más atención. El cambio fue notable. Sin embargo, es necesario indicar que el tipo de atención que presentaba es involuntaria, pues se produce de forma automática ante estímulos intensos. Lo deseable es que esta orientación atencional sea controlada según la propia voluntad del menor, y que no sean los rasgos atrayentes de Aisoy1.

\subsection{Caso 3}

Puede verse que en "Música" (ver Figura 7), no se ha logrado nombrar los animales (ítem 2), realizar comentarios y responder a preguntas acerca del cuento (ítems 7 y 8) y cantar las canciones (ítem 10) obteniendo la misma puntuación que inicialmente, un 1. Todas están relacionadas con la comunicación verbal, puesto que todavía el menor no ha desarrollado dicha capacidad fluidamente, sino solo alguna palabra como "no", resultando por tanto difícil conseguir dichos objetivos a corto plazo.

Sí se han mejorado otros aspectos, obteniendo una puntuación de 1 a 2 puntos como en identificar características de cada animal (ítem 3 ) y con 4 y 5 puntos, como asociar las imágenes de los animales con sus onomatopeyas (ítem 4) o mostrar interés y seguir la lectura del cuento (ítems 5 y 6 ).

Respecto a la relación con Aisoy1, el niño siempre tenía ganas de jugar. Lo tocaba y le enseñaba las tarjetas previamente a iniciar cualquier actividad, observándose por tanto que memorizaba las acciones anteriores y sabía cómo relacionarse con el robot.

\subsection{Caso 4}

Los resultados son en algunos aspectos mejores que al inicio, aunque en general no se ha progresado ampliamente como en otros casos (ver Figura 8 ). Se obtiene una puntuación de 5 con las actividades relacionados con "Música", como conocer 


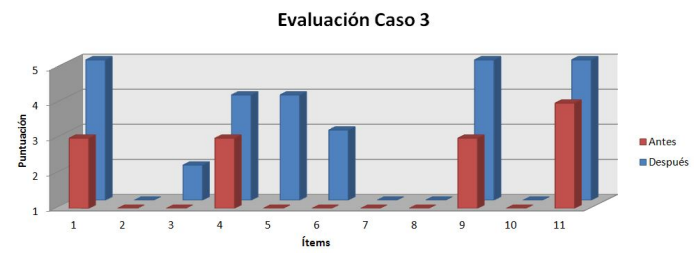

Figura 7: Modelo de evaluación Caso 3

los animales y sus onomatopeyas (ítem 1), nombrar los animales (ítem 2), identificar características de cada uno (ítem 3) y asociar las imágenes de ellos con sus onomatopeyas (ítem 4).

Asimismo, con respecto a "Puzle de las emociones" y "Reconocimiento de emociones" se ha mejorado completamente en conocer las emociones (ítem 21) e identificarlas en el robot (ítem 22) y clasificar objetos según color (ítem 29). Con la actividad "Libros y cuentos" se destaca el objetivo mostrar interés en la lectura del cuento (ítem 5) consiguiendo 4 puntos respecto a 1 en un principio. Esto significa que se ha mejorado la capacidad de atención, algo muy positivo.

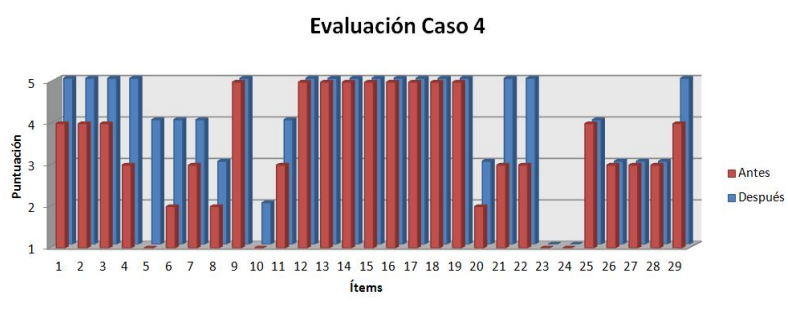

Figura 8: Modelo de evaluación Caso 4

\section{Conclusiones}

Como conclusión, los resultados son satisfactorios, pues la mayoría de los objetivos se han mejorado o se han mantenido como un principio, pero en ningún caso ha empeorado tras las sesiones de actividades con el robot Aisoy1 por rechazo de los niños. Observando las gráficas que comparan los resultados obtenidos de cada caso antes y después, se ha incrementado sobretodo en los caso 1 y 4 , especialmente en el primero, obteniendo una calificación en casi todos los ítems de 5 puntos.

En relación a las relaciones personales, tienden a mantener un bajo interés hacia otras personas a la hora de comunicarse. Sin embargo, interactúan de forma fluida con el robot incluso aunque tenga apariencia muy simple. Un aspecto importante del robot es su apariencia. Debido a su forma de animal, como un gato, o incluso un niño planteó que era un fantasma, es capaz de empatizar rápidamente, no creando así ningún rechazo que afectase al desarrollo de las sesiones. Además incluye luces y una gran variedad de sonidos y movimientos para expresiones faciales y gestos, para reforzar positivamente al niño y mantener su atención. Además, el comportamiento repetitivo del robot le aumenta el interés y lo estimula a imitarlo espontáneamente, lo que les ayuda a entender el significado de esa información social, así como mejorar las habilidades de contacto visual directo [9], [10].

Que el robot Aisoy1 sea un robot social de bajo coste supone en un primer lugar una gran ventaja, pues es accesible a mayor número de personas. Además, al integrar una Raspberry Pi como gestor de todos los sensores y actuadores y a un entorno de programación sencillo, ha sido posible añadir hardware externo a Aisoy1 fácilmente, consiguiendo aumentar el número de funciones del robot. Igualmente, se han empleado códigos de programación externos al software propio el robot, es decir, forman parte del software de Raspberry Pi. Ejemplos son: el comando "omxplayer" como reproductor de vídeo y el módulo "pygame" como reproductor de música y en reconocimiento de colores.

Sin embargo, el robot presenta limitaciones que han incapacitado el diseño de actividades que en un principio fueron ideadas. Por ejemplo, la tecnología de reconocimiento de voz ASR sería empleado para mantener conversaciones con los niños, hablar sobre sus emociones, así como para validar las respuestas de las actividades, en vez de emplear el código QR.

Otra limitación es la cámara integrada en Aisoy1, puesto que aunque las funciones para tomar fotos y para reconocer códigos QR estaban operativas, el reconocimiento de rostro no funciona de forma óptima, por ello no se ha podido emplear en ninguna aplicación práctica. Aunque las funciones del lenguaje de programación de Aisoy1 están basadas en OpenCV, tampoco se podía incluir ninguna mejora empleando códigos de dicho entorno, imposibilitando también el desarrollo de aplicaciones como el reconocimiento de emociones.

Igualmente, otra limitación ha sido emplear altavoces externos adicionales, ya que la señal de altavoz se puede aumentar o disminuir con un amplificador de sonido incorporado en la Raspberry Pi, por lo que se puede escuchar al nivel que se desee. Pero si el nivel de ruido en un ambiente si es mayor de lo normal se dificulta el entendimiento de Aisoy1.

Una última limitación es que la movilidad de Aisoy1 no es completa al no poseer extremidades, lo que reduce la capacidad de emplear actividades con seguimiento de instrucciones con los niños y 
niñas.

En la actualidad, Aisoy1 no está capacitado para realizar las actividades de forma individual según lo comentado anteriormente, aunque como apoyo a las terapias con un experto es una herramienta recomendable. Además, no podía implementarse en más de una sesión a la semana para no causar rechazo en los menores, alternándose de este modo con sesiones únicamente con las terapeutas.

\section{Agradecimientos}

Agradecer al Centro de Atención Infantil Temprana Jardines de La Pipa. Sin su colaboración no podría haberse llevado a cabo el proyecto.

\section{English summary}

\section{STUDY AND APPLICATION OF A SOCIAL ROBOT TO CHILDREN WITH EARLY CARE NEEDS}

\begin{abstract}
Although industrial robotics has been widely developed in the manufacturing industry over the last thirthy years, service robotics is under development and research, presenting great possibilities for innovation and with great growth potencial, where robots are increasingly capable of interact with people. Based on this ability, they will play an essential role in human society in the near future. In this study, the motivation is to analyze how the social robot Aisoy1 works from the technological point of view, and to apply all its potential in the design of activities that help people with some degree of disability. The results obtained are positive, because knowing that a treatment is developed over a long period of time, with the robot's support in a short period of time there have been improvements in communication, such as vocalization, repetition of words, association of emotions and colors or better interaction with the environment, which at the beginning did not exist or were limited.
\end{abstract}

Keywords: Social robotics, Aisoy1, Early Attention, Python, Raspberry Pi.

\section{Referencias}

[1] GAT, G. D. A. T., (2000) Libro Blanco de Atención Temprana, Madrid.

[2] Cho, S. J., and Ahn, D. H., (2016) Socially assistive robotics in autism spectrum disorder, Hanyang Medical Reviews, 36(1), pp 17-26.

[3] Esteban, P. G., (2014) Cooperation and Competition in Emotional Robot Societies, Doctoral dissertation, Universidad Rey Juan Carlos.

[4] Racero, A. R., (2016) Integración de robot social en sistema domótico, Universidad de Sevilla.

[5] Aisoy Robotics,

https://www.aisoy.es/aisoy1-spec.html. Fecha de acceso: Junio 2018.

[6] Insua, D. R., García, D., Gómez, P., and Redondo, A., (2011) Máquinas que perciben, sienten y deciden, Real Academia de Ciencias Exactas, Físicas y Naturales, 105(1), pp 99-106.

[7] Aisoy Robotics S.L., (2016) Manual de Usuario de Aisoy1 V5.

[8] Villegas, M. A., (2017), Atención temprana desde la perspectiva de la robótica social: propuesta de terapias con el robot aisoy, Trabajo fin de estudios del máster en ciencias del sistema nervioso, Universidad de Almería.

[9] Robot Charlie, https://www.lauraboccanfuso.com/projectdetails. Fecha de acceso: Junio de 2018.

[10] Michaud, F., Duquette, A., and Mercier, H., (2006) Investigating the use of a mobile robotic toy as an imitation agent for children with autism, Proceedings International Conference on Epigenetic Robotics: Modeling Cognitive Development in Robotic Systems, París.

[11] MacDorman, K. F., Kageki, M., and Mori, M., (2012) The uncanny valley, IEEE Robotics and Automation Magazine, 19(2), pp 98100.

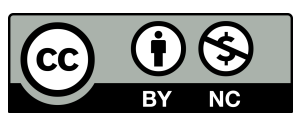

(C) 2018 by the authors. Submitted for possible open access publication under the terms and conditions of the Creative Commons Attribution CC-BY-NC 3.0 license (http://creativecommons.org/licenses/by-nc/3.0/). 